\title{
Distribution of the Mooring Data Buoy Based on Small Fishing Boat
}

\author{
Chen Yonghua ${ }^{a}{ }^{*}$, Liu Qingkui ${ }^{b}$, Jiang Jingbo, Ni Zuotao and Li Xiaolong \\ Institute of Oceanology, Chinese Academy of Sciences, Qingdao, Shandong Province, 266071, China \\ a yonghuachen@aliyun.com, bliuqk5102@163.com \\ *corresponding author
}

Keywords: Distribution, Mooring data buoy, Small fishing boat, Safety and efficiency

\begin{abstract}
With the further advance of ocean research and the national security needs, the mooring data buoy has been widely used as an important part of ocean engineering high-tech research. How to deploy them in a convenient and economic way is very important. In the past, the deployment is often accomplished by large special vessel, which needs a lot of manpower and material resources. Here a novel deploying method is introduced for mooring data buoy based on small fishing boat. This method employs a small fishing boat with two pulleys (one is served as movable pulley, the other is stable pulley.) and a winch. By way of the relay, it drops all the mooring chains into the water step by step. At last, the anchor is made into ocean water. After several experiments inspection, this anchor-last deploying method for mooring data buoy is safe and efficient.
\end{abstract}

\section{Introduction}

Fully automated data buoys are commonly used in coastal and offshore waters to monitor the atmospheric and sea conditions prevailing at the site. Usually moored buoys can measure and transmit barometric pressure; wind direction, speed, and gust; relative humidity; visibility above the sea; air and sea temperature; and wave energy spectra from which significant wave height, dominant wave period, and average wave period are derived. Even the direction of wave propagation is measured on many moored buoys. Ocean currents, salinity, turbidity, chlorophyll, dissolved oxygen are measured at the same time [1]. These data acquisition systems collect real-time meteorological and oceanographic measurements for operational and research purposes. Data from the buoy can be transmitted real-time and stored internally. The size of the data buoy mostly is larger than $3.0 \mathrm{~m}$ to maintain its stability and ensure that accurate data obtained. It is recommended that a single rectangular block of concrete/iron weighing at least $2000 \mathrm{~kg}$ be used to anchor the data buoy. What is more, the buoy may be moored using an all-chain mooring and hundreds of meters of more than $19 \mathrm{~mm}$ diameter, proof-coil, low-carbon steel chain is used to connect the anchor to the surface buoy. Connections are made using an appropriate combination of safety shackles, swivels and thimbles [2,3]. All of these together constitute a very complex system and the deployment usually needs a relatively large vessel and the special equipment on board. Large crane, the vast deck space, anchor chain storage hole and anchor chain release machine are shown in fig.1.

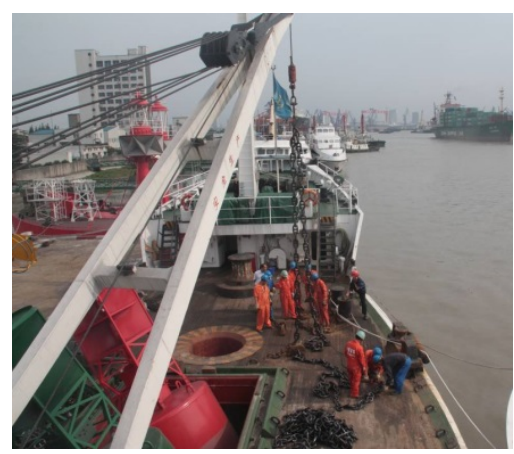

Fig. 1 A special vessel for the buoy deployment 
But the disadvantage is that the large vessels, which is expensive and hard to access. Here a novel deploying method is introduced for mooring data buoy based on small fishing boat (the tonnage is about $100 \mathrm{t}$ ) which is relatively economic $[4,5]$.

\section{Preparation for Distribution}

There is a lot of work to do before the distribution of the mooring data buoy. The main preparatory work is listed as follows.

\subsection{Tested in harbour}

After being checked and sealed, the buoy is usually tested about 48 hours before deployment. It is removed from shore and moored in the harbour to check if the buoy data is OK. If everything is $\mathrm{OK}$, the buoy can be deployed. If there is some doubt about the signal, it cannot be deployed and a complete overhau of the buoy will be made until it is fine.

\subsection{Arrangement of anchoring chain}

Moorings fix the buoy to the seabed including mooring chain and anchor. Buoy design must account for the behaviour of the buoy given applicable wind, wave and current conditions and tanker sizes. This determines the optimum mooring arrangement and size of the various mooring leg components. According to the depth of the mooring point, moorings maybe include a few of anchor chains with the length of about 30 meters. After put the chain on the vessel deck, the chains sre connected together and arranged in accordance with " $S$ " shape. One end which is connected to the anchor is arranged at the end of the small fishing boat, and the other end which is connected to the buoy is put in the front of the small fishing boat. Because the vessel is small, the side of the deck may be used to arrange the chains.

\subsection{Towage of buoy body}

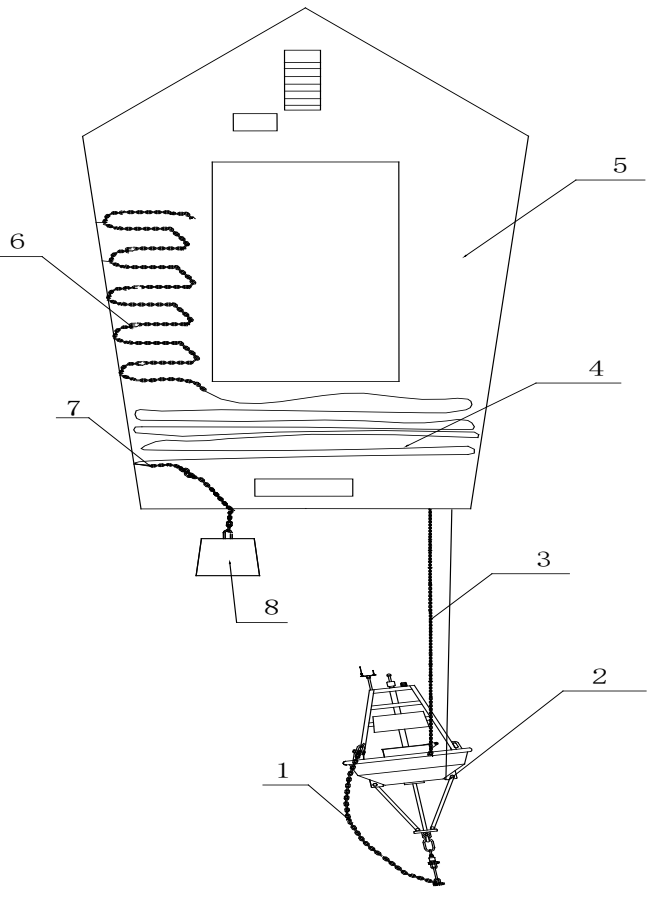

Fig. 2 Arrangement of anchor chain and towage of the buoy body

1) chain on buoy body; 2) buoy body; 3) towage rope; 4) chainI;

5 ) small fishing boat; 6) chainII; 7) rope fixed anchor, 8) anchor block.

Two ropes are used to connect the buoy body and the small fishing boat. One is tied upper of the 
buoy body, and the other is tied down of the buoy body (Fig. 2 and Fig. 3). According to adjusting the length of the two ropes, the buoy body can follow with the small fishing boat keeping the balance in the sea. It can neither be embed into water, nor be excessive fade away. The speed of the small fishing boat does not exceed six knots.

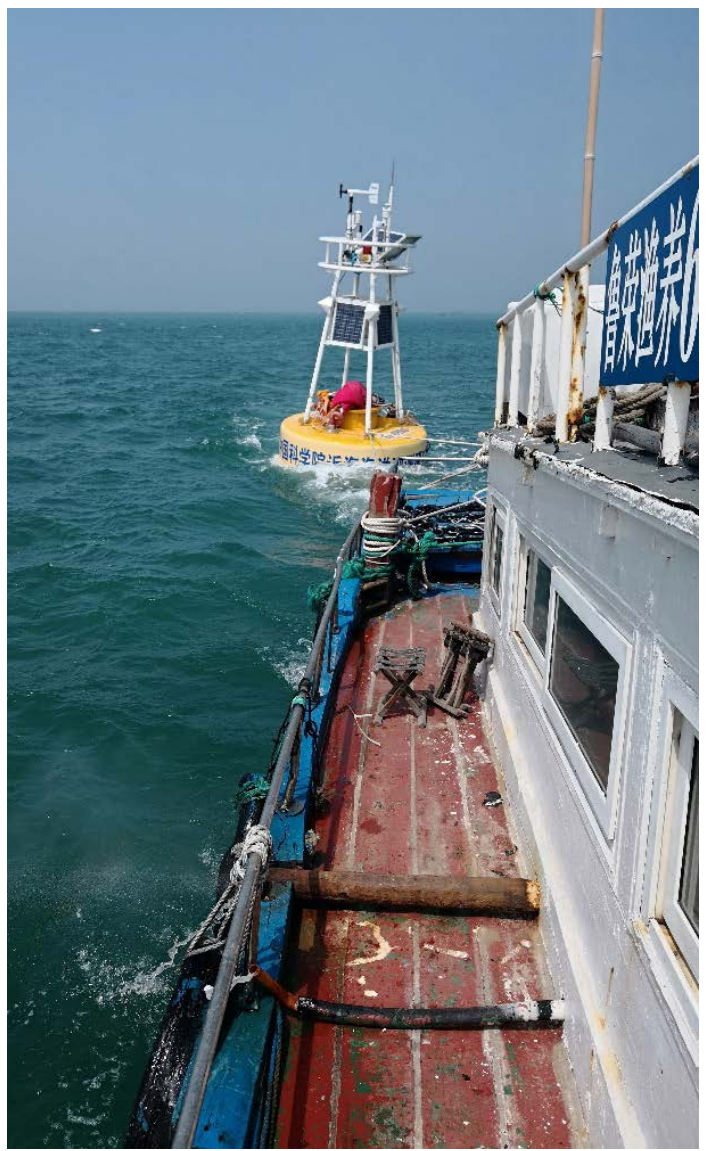

Fig. 3 Practicality picture of the towing of the buoy body at sea

\subsection{Distribution}

Here anchor-last deployments are empolyed. In anchor-last deployments, the buoy body is deployed first and the mooring paid out as the pulley steams away from it. If possible, the line of deployment should be about 3 times the depth contour in which the buoy is to be deployed. Once all the mooring chain is in the water the anchor is deployed at the position which confers the greatest probability of it landing at the desired depth and location.

As shown in Fig. 4, the detailed deployment is described as follows. When the small fishing boat takes the buoy system including buoy body, mooring chain and anchor to the desired position, stop the ship and choose one person as commander. Firstly, the movable pulley is put and pulley in the front of the small fishing boat is fixed, and release rope is used to connect them together. One end of the release rope is coiled on the winch, and the other is fixed on stable place. Secondly, cross the chain II to the movable pulley and connect it and the chain on buoy body. Thirdly, the release rope is spooled off the winch and chain II is released into water. When the movable pulley is moved to the tail of the vessel, the chain is fixed on the deck and the movable pulley is moved to the front of the vessel. At the same time, the release rope is spooled on the winch and the chain I is through the movable pulley. Fourthly, repeat the last step again and again, and all the chains are put into the water. Finally, cut the rope fixed anchor and the anchor is released to the bottom of the sea and the buoy takes its place. So far the buoy deployment is completed.

If problems arise with gear, or if sea conditions become unfavourable during the deployment, it can be aborted, with mooring and buoy being hauled back. 


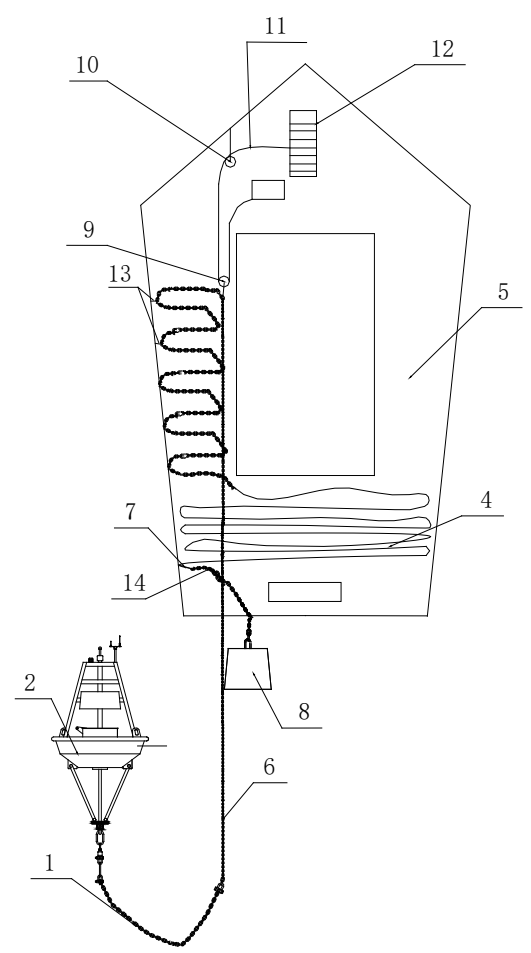

Fig. 4 Release process of the buoy based on small fishing boat

1) chain on buoy body; 2) buoy body; 3) towage rope; 4) chainI; 5) small fishing boat; 6) chainII; 7) rope fixed anchor, 8) anchor block;

9) movable pulley; 10) fixed pulley; 11) release rope; 12) winch; 13) ropes fixed chain, 14) chain III.

\section{Conclusions}

Anchor-last deployments are much safer than other methods when small fishing boat is employed, and they permit adjustments during the deployment process. It should be pointed out that the anchor sinks after being deployed, the drag caused by the mooring rope increases dramatically. Engineering studies have shown that, once the anchor is let go, tension on the mooring increases steadily as the anchor descends and reaches its highest point just before the moment of impact, when it is about equal to the static weight of the anchor. The result is that the anchor and the buoy move together in the horizontal dimension, each one being pulled by the other. In a word, this method is a very effective way to deploy the buoy basing on small fishing boat.

\section{Acknowledgements}

I thank Profess F. Yu and senior engineer S.R. Li for technical help. The project was financially supported by Key research and development of science and technology Program (Grant No. 2017YFC1403406), by Science Fund for Technology Strategic Pilot of the Chinese Academy of Sciences (XDA11040306), by major scientific research equipment R \& D projects of Chinese Academy of Sciences (Grant No. YZ201522 and No. YZ201625) .

\section{References}

[1] Maganioti, A.E., Chrissanthi, H.D., Charalabos, P.C., Andreas, R.D., George, P.N. and Christos, C.N. (2010) Cointegration of Event-Related Potential (ERP) Signals in Experiments with Different 
Electromagnetic Field (EMF) Conditions. Health, 2, 400-406.

[2] Bootorabi, F., Haapasalo, J., Smith, E., Haapasalo, H. and Parkkila, S. (2011) Carbonic Anhydrase VII—A Potential Prognostic Marker in Gliomas. Health, 3, 6-12.

[3] Chang Zong-yu, Tang Yuan0guang, Li Hua-jun, et al. Analysis for the Deployment of Single-Point Mooring Buoy System Based on Multi-Body Dynamics Method[J]. Chian Ocean Eng. 2012, 26(3) :495-506

[4] Kaliyaperumal, P., Venkatesan, R., Senthilkumar, P., et al. Design, Analysis and Installation of Offshore Instrumented Moored Data Buoy System[J]. 2015 (4) :181-194.

[5] KRIVTSOV Vladimir, LINFOOT Brian, HARRIS Robert E. Effects of the shape and size of a mooring line surface buoy on the mooring load of wave energy converters [J]. J Chongqing Univ: Eng Ed [ISSN 1671-8224], 2012, 11(1): 1-4. 